\title{
Sleep Quality, Perceived Stress, and Caffeinated Drinks Intake in Psychiatry Residents: A Cross-Sectional Study
}

\author{
Carmen Concerto, MD, ${ }^{1,2}$ Claudio Conti, MD, ${ }^{3}$ Maria R. Muscatello, MD, PhD, ${ }^{3}$ \\ Maria S. Signorelli, MD, PhD, ${ }^{2}$ Rocco Zoccali, MD, ${ }^{3}$ Diego Coira, MD, ${ }^{4}$ \\ Eugenio Aguglia, $\mathrm{MD}^{2}$ and Fortunato Battaglia, $\mathrm{MD}, \mathrm{PhD}^{1,4}$
}

Background: Medical residencies are highly demanding and stressful and have been associated with mental and emotional problems. Studies that evaluated this relationship in Italian psychiatry residents are scarce. In this study, we examined sleep quality and its association with perceived stress and caffeinated beverages consumption in Italian psychiatry residents.

Methods: Seventy-two PGY1-5 psychiatry residents at two University Hospitals in Italy were asked to complete an anonymous questionnaire. The Pittsburgh Sleep Quality Index and Epworth Sleepiness Scale were used to determine the sleep quality and the level of daytime sleepiness (EDS). In addition, we investigated perceived stress and caffeinated drinks consumption (coffee, tea, soda, energy drinks).

Results: Seventy psychiatry residents responded to the survey (97.2\% response rate) $(M=34.3 \%, F=65.7 \%$; mean age $=30.5 \pm 4.2$ SD years). $44.3 \%$ had poor sleep quality and $15.7 \%$ had abnormal EDS. $64.3 \%$ reported significant perceived stress. Perceived stress score and coffee consumption were associated with greater likelihood of poor sleep quality.

Conclusions: Psychiatry residents have high prevalence of poor sleep quality. Future longitudinal studies are needed to investigate causality and identify appropriate coping strategies and lifestyle changes aimed to improve mental health in psychiatry trainees.

Keywords: caffeine, energy drinks, psychiatry residents, sleep, stress

\section{Introduction}

$\mathbf{M}$ EDICAL RESIDENTS FACE high levels of subjective stress during their academic training. ${ }^{1}$ The academic overload, lack of time for leisure, financial difficulties, exhaustion, overwhelming patient care duties, and overnight calls are often associated with sleep deprivation and high psychological toxicity. ${ }^{2,3}$ Sleep-deprived trainees across residencies show impaired academic performance, unprofessional behavior, ${ }^{4}$ and abnormal emotional processing. ${ }^{5}$

Caffeinated beverages such us coffee, tea, soft drinks, and energy drinks are often used to promote alertness, cope with stress, and enhance cognitive performance. ${ }^{6}$ Caffeine intake has a well-known disruptive effect on sleep ${ }^{7}$ and may exaggerate the sympathetic-adrenal medullary responses to stressful events, negatively affecting resident's quality of life. ${ }^{8}$

To date, the epidemiological data on sleep quality in medical trainees are limited and not representative of all nationalities. Psychiatry trainees in Italy are required to perform the same duties and work hours as an attending. In addition, the duration of psychiatry programs is 5 years (PGY1-5) and residents have to attend classes and take multiple exams (10-12 each year, both oral

\footnotetext{
${ }^{1}$ Department of Interprofessional Health Sciences \& Health Administration, School of Health and Medical Sciences, Seton Hall University, South Orange, New Jersey.

${ }^{2}$ Department of Clinical and Experimental Medicine, Psychiatry Unit, University of Catania, Catania, Italy.

${ }^{3}$ Department of Neurosciences, Psychiatry Unit, University of Messina, Messina, Italy.

${ }^{4}$ Department of Psychiatry and Behavioral Medicine, Hackensack University Medical center, Hackensack, New Jersey.

(C) Carmen Concerto et al. 2017; Published by Mary Ann Liebert, Inc. This is an Open Access article distributed under the terms of the Creative Commons Attribution License, which permits unrestricted use, distribution, and reproduction in any medium, provided the original work is properly cited.
} 
and written exams). Residents failing to pass the yearly exams are not allowed to retest and are dismissed from the program. Thus, examination stress adds to the trainees' psychological burden.

To the best of our knowledge, only one study has investigated sleep duration in on-call psychiatry residents, demonstrating that the total number of pages received and the number of admissions best explain the variance in the hours of sleep. ${ }^{9}$ Thus, sleep quality and daytime sleepiness (EDS), and their association with caffeinated beverage intake in psychiatry trainees still need to be addressed.

Concerns have been expressed regarding the potential for caffeinated drinks to negatively affect mental health. Based on previous research, we hypothesized that caffeinated beverage intake and perceived stress could make statistically significant contributions to the prediction of sleep quality in psychiatry residents. Our results might be of importance in developing prevention and early intervention strategies aimed at improving sleep and mental health in psychiatry residents.

\section{Materials and Methods}

Between July and September 2013, we conducted this cross-sectional survey at two psychiatry residency programs at the University of Catania and Messina School of Medicine, Italy. The University institutional review boards approved the study.

In both Universities, the participants $(N=72)$ were PGY1-5 psychiatry residents. After a scheduled lecture, 70 residents returned a completed anonymous, selfadministered questionnaire in a sealed envelope. The first page of the questionnaire contained all the necessary information for informed consent. In the place

Table 1. Demographic Characteristics of THE StUdy SAMPLE

\begin{tabular}{lcc}
\hline & Frequency & Percentage \\
\hline Sex & & \\
Female & 46 & 65.7 \\
Male & 24 & 34.3 \\
Age & & \\
25-30 & 55 & 78.6 \\
$31-35$ & 8 & 11.4 \\
$36-40$ & 5 & 7.2 \\
$40+$ & 2 & 2.8 \\
PGYs & & \\
PGY-1 & 18 & 25.7 \\
PGY-2 & 13 & 18.6 \\
PGY-3 & 12 & 17.1 \\
PGY-4 & 16 & 22.9 \\
PGY-5 & 11 & 87.1 \\
Living single & 61 & \\
University & & 60 \\
Catania & 42 & 40 \\
Messina & 28 & \\
\hline PGY, postg
\end{tabular}

PGY, postgraduate year. of a signature line, we included the following statement: "the return of this survey is your consent to participate in the research." Table 1 shows the demographic characteristics.

\section{Study measures}

We used established instruments to assess sleep quality, EDS, and perceived stress. The survey also included questions about demographic characteristics, smoking habit (average cigarettes/day during the previous week), and caffeinated drink intake (cup coffee and tea/day, caffeinated soft drinks/day, energy drinks during the previous week). For regression analysis, these behavioral variables were dichotomized (user/non-user).

Epworth Sleepiness Scale (ESS), is a brief self-report instrument designed to identify persons with excessive EDS. It addresses the likelihood of falling asleep from 0 (no chance of dozing) to 3 (high chance of dozing) during commonly encountered situations. A total score greater than 10 indicates probable EDS. ${ }^{10}$ This measure has high test-retest reliability and internal consistency. ${ }^{11}$

Sleep quality was assessed using the Pittsburgh Sleep Quality Index (PSQI). ${ }^{12}$ PSQI is a self-report scale consisting of queries about multiple sleep-related variables over the preceding month, using Likert and open-ended response formats. The PSQI addresses subjective sleep quality, sleep latency, sleep duration, habitual sleep efficiency, sleep disturbances, use of sleeping medication, and daytime dysfunction. A total score greater than 5 is considered indicative of poor sleep quality, whereas a score of 5 or less is considered indicative of good sleep quality. ${ }^{12}$ Internal consistency reliability and construct validity of the PSQI were previously reported. ${ }^{13}$

Perceived Stress Scale (PSS-10). Perception of stress takes place when a subject realizes that situational demands exceed his or her resources. ${ }^{14}$ A 10 -item perceived stress scale (PSS-10) was previously validated and used to address stress in students and trainees. ${ }^{15}$ Answers are given on a 5-point Likert scale ranging from 1 (never) to 5 (very often), with higher scores reflecting greater perceived stress. A score above 14 is considered to reflect significant perceived stress. ${ }^{16}$

All instruments have been translated in Italian and have been used in previous studies. ${ }^{1,17,18}$

\section{Statistical analysis}

Caffeinated drink intake, sociodemographic and behavioral covariates (smoking habit and perceived stress), sleep quality, and EDS were summarized using descriptive statistics. $\chi^{2}$ Test was used to investigate the relationship between age and gender and sleep quality. A logistic regression analysis was conducted to determine the impact of sociodemographic (model 1) and behavioral variables (model 2) on sleep quality. Data were analyzed using the SPSS (version 19.0) program. $p$-value $<0.05$ was taken as the level of significance. Mean are \pm SE. 
Table 2. Pittsburgh Sleep Quality Index Parameters in Psychiatry Residents (Mean \pm SE)

\begin{tabular}{ll}
\hline Sleep quality & $1.01 \pm 0.11$ \\
Sleep latency & $1.04 \pm 0.09$ \\
Sleep duration & $0.97 \pm 0.08$ \\
Sleep efficiency & $0.43 \pm 0.07$ \\
Sleep disturbances & $1.00 \pm 0.14$ \\
Sleep medications & $0.53 \pm 0.1$ \\
Daytime dysfunction & $0.51 \pm 0.07$ \\
Total PSQI & $5.30 \pm 0.3$ \\
\hline
\end{tabular}

PSQI, Pittsburgh Sleep Quality Index.

\section{Results}

The demographics characteristics of the respondents $(N=70)$ are summarized in Table 1 . The average age of the respondents was 30.5 years (4.2 SD), $75.7 \%$ were coffee drinkers (13.5 \pm 1.3 espressos/week), $52.9 \%$ were tea drinkers ( $1.3 \pm 0.2$ cups/week), $65.7 \%$ consumed regularly caffeinated sodas $(2.9 \pm 0.4$ cans/week $)$, and $48.6 \%$ consumed energy drinks $(0.27 \pm 0.06$ cans/week $) .22 .9 \%$ of the responders were smokers $(11.3 \pm 4.4$ cigarettes/week) and the mean PSS-10 score was 7.01 \pm 6.5 .

Residents' mean sleep duration per night was $6.3 \pm$ 0.8 hours and the median sleep latency was $35.85 \pm 21.3$ minutes. PSQI scores are reported in Table 2. The mean PSQI was $5.03 \pm 3 ; 44.3 \%$ residents were poor sleepers and $8.5 \%$ used sleeping pills in the last month (Zolpidem). There was no relationship between age, gender, and sleep quality ( $\chi^{2}$ test: $\left.p>0.05\right)$. In addition, the mean ESS score was $5.9 \pm 3.1$ and the prevalence of excessive EDS (ESS score $\geq 10$ ) was $15.7 \%$.

To identify factors associated with poor sleep quality, we used two logistic regression models: model 1 for demo- graphic variables and model 2 for behavioral variables. Results are summarized in Table 3. The demographic variables were not associated with increased odds for poor sleep. The Nagelkerke's $\mathrm{R}^{2}$ suggests that the model explains only $7.9 \%$ of the variation (chi square $=4.3, p=0.6$ ).

On the contrary, model 2 indicated that PSS-10 score [Adjusted Odds Ratio (AOR) 1.289 (1.1, 1.4)] and number of cups of coffee consumed in the previous week [AOR $1.05(1.02,1.08)]$ increase the odds for poor sleep in psychiatry residents. The predictors as a set reliably distinguished between good and poor sleepers (chi square $=44.2, p<0.000$ with $\mathrm{df}=6$ ). The Hosmer and Lemeshow test of goodness of fit suggests the model is a good fit to the data as $p=0.8(>0.05)$. The Nagelkerke's $\mathrm{R}^{2}$ suggests that the model explains roughly $62.7 \%$ of the variation. Model 2 is correctly classifying $78.6 \%$ of the cases. Furthermore, multicollinearity was excluded as indicated by the Variance Inflation factor $<5$ for all the behavioral variables. Interestingly, PSS-10 and PSQI total scores were highly correlated $(P=0.0001)$.

\section{Discussion}

In this study, we investigated sleep quality in Italian psychiatry residents (PGY1-5). Our data indicate a high prevalence of poor sleep quality. Furthermore, we identified predictors for increased odds of poor sleep quality.

The study was carried out in Southern Italy, an area characterized by strong coffee consumption $(36.4 \%$ of general population, 14-20 espressos/week) and relatively low tea, soft drinks, and energy drink intake. ${ }^{19}$ This pattern was confirmed in our study. ${ }^{20} 44.3 \%$ psychiatry residents had poor sleep quality with a mean duration of sleep

Table 3. Adjusted Results for the Association Between Demographic (Model 1) and Behavioral (Model 2) Variables and Sleep Quality

\begin{tabular}{|c|c|c|c|c|c|c|c|c|}
\hline & $B$ & $S E$ & Wald & $d f$ & Sig. & $\operatorname{Exp}(B)$ & $\begin{array}{c}95 \% \text { CI } \\
\text { for lower }\end{array}$ & $\begin{array}{c}\text { Exp }(B) \\
\text { upper }\end{array}$ \\
\hline \multicolumn{9}{|c|}{ Demographic variables (Model 1) } \\
\hline University (Messina) & 0.07 & 0.002 & 0.012 & 1 & 0.912 & 1.032 & 0.245 & 2.332 \\
\hline PGY (1-2) & 1.461 & 1.002 & 2.125 & 1 & 0.145 & 4.309 & 0.604 & 30.719 \\
\hline PGY (2-3) & 1.627 & 0.994 & 2.681 & 1 & 0.102 & 5.091 & 0.726 & 35.715 \\
\hline PGY (3-4) & 1.509 & 0.987 & 2.339 & 1 & 0.126 & 4.523 & 0.654 & 31.287 \\
\hline PGY (4-5) & 1.254 & 0.937 & 1.794 & 1 & 0.18 & 3.506 & 0.559 & 21.977 \\
\hline Age & 0.006 & 0.066 & 0.008 & 1 & 0.929 & 0.994 & 0.874 & 1.131 \\
\hline Gender (female) & 0.094 & 0.549 & 0.029 & 1 & 0.864 & 1.099 & 0.375 & 3.222 \\
\hline Marital status (single) & 0.083 & 0.044 & 0.017 & 1 & 0.954 & 1.121 & 0.432 & 2.898 \\
\hline Constant & 1.355 & 2.177 & 0.387 & 1 & 0.534 & 0.258 & & \\
\hline \multicolumn{9}{|c|}{ Behavioral variables (Model 2) } \\
\hline PSS & 0.254 & 0.077 & 10.864 & 1 & $0.001 * *$ & 1.289 & 1.108 & 1.498 \\
\hline ED/week & 0.136 & 0.184 & 0.544 & 1 & 0.461 & 1.146 & 0.798 & 1.644 \\
\hline Soft drinks/week & 0.039 & 0.03 & 1.709 & 1 & 0.191 & 0.962 & 0.908 & 1.019 \\
\hline Cup tea/week & 0.109 & 0.065 & 2.768 & 1 & 0.096 & 0.897 & 0.789 & 1.02 \\
\hline Cup coffee/week & 0.048 & 0.015 & 10.684 & 1 & $0.001 * *$ & 1.05 & 1.02 & 1.08 \\
\hline Cigarettes/week & 0.001 & 0.002 & 0.31 & 1 & 0.578 & 0.999 & 0.995 & 1.003 \\
\hline Constant & 5.776 & 1.566 & 13.602 & 1 & 0 & 0.003 & & \\
\hline
\end{tabular}

$* * p<0.01$.

ED, energy drinks; PSS, Perceived Stress Scale. 
per night of about 6 hours. As previously reported, ${ }^{21}$ such a sleeping habit is likely to have a major impact on residents' abilities to perform their work. In addition, sleepdeprived medical trainees often report stress and fatigue. ${ }^{21}$ For this reason the Accreditation Council for Graduate Medical Education (ACGME) requires duty-hour limits, and residency programs offer their residents an educational presentation on sleep deprivation. ${ }^{22}$

Our results are consistent with previous studies performed in other medical specialties. ${ }^{2,23,24}$ Furthermore, as previously reported in general population, ${ }^{25,26,27}$ in our study, poor sleep quality was found to be associated only with perceived stress ${ }^{2,3,28}$ and coffee drinking, while the use of other caffeinated drinks was not associated with poor sleep quality in trainees. This might be due to the caffeinated drink habit in Southern Italy. ${ }^{20} \mathrm{~A}$ significant percentage of residents demonstrated high score in the ESS, indicating increased sleepiness and higher risk of falling asleep during daily activities. Our results are in accordance with previous studies. ${ }^{29,30}$ Excessive EDS might expose the residents to increased risk of car accident $\mathrm{S}^{31}$ and is associated with poor judgment, decrease in attention, and unprofessional behavior. ${ }^{32}$

It is important to emphasize that our results are purely associative and we should consider causality with caution. Although there are several studies that demonstrated that coffee and caffeine have a negative impact on sleep (increased sleep latency, reduced total sleep time and efficiency, decrease in slow waves, and increased arousals), ${ }^{33}$ it is common knowledge that coffee has a positive effect on working performances and a moderate intake is not considered a health hazard. ${ }^{34}$ It is thus possible that sleep-deprived residents drink more coffee to overcome sleepiness and that coffee intake does not disrupt sleep. Future studies should investigate in depth a possible causal link.

The study has a few limitations. The study was performed at two Italian medical schools, both located in the same geographical area (Sicily), and the residents were all Caucasian. The study design (cross-sectional) implies that inferences with respect to causality should be made with caution. Thus, our results need to be replicated in larger studies involving a more diverse population. In addition, few residents used Zolpidem as an occasional sleeping aid and this drug might affect sleep quality. ${ }^{35}$ Thus, an in-depth analysis of sleep quality in residents using sleep medications should be performed in future studies. Furthermore, we did not assess residents' height and weight, which can affect caffeine metabolism.

In conclusion, we showed for the first time that Italian psychiatry residents exhibit high prevalence of poor sleep quality and we identified predictors. Our results are in keeping with our previous work demonstrating a similar association in graduate podiatric students. ${ }^{36}$ Thus, this study fills a gap in the literature as previous researches mostly focused on undergraduate students, graduate students, and trainees, and data on psychiatry residents are scarce. Our results might be used to implement changes in the working environment, aimed to minimize the negative impact on sleep and mental health during psychiatry residency.

\section{Acknowledgment}

The authors thank psychiatry residents who responded to the survey.

\section{Author Disclosure Statement}

No competing financial interests exist.

\section{References}

1. Radcliffe C, Lester H. Perceived stress during undergraduate medical training: A qualitative study. Med Educ. 2003;37:32-38.

2. Baldwin DC, Jr., Daugherty SR. Sleep deprivation and fatigue in residency training: Results of a national survey of first- and second-year residents. Sleep. 2004;27:217-223.

3. Dyrbye LN, West CP, Satele D, Boone S, Tan L, Sloan J, et al. Burnout among U.S. medical students, residents, and early career physicians relative to the general U.S. population. Acad Med. 2014;89:443-451.

4. Tempski P, Bellodi PL, Paro HB, Enns SC, Martins MA, Schraiber LB. What do medical students think about their quality of life? A qualitative study. BMC Med Educ. 2012;12:106

5. Zohar D, Tzischinsky O, Epstein R, Lavie P. The effects of sleep loss on medical residents' emotional reactions to work events: A cognitive-energy model. Sleep. 2005;28:47-54.

6. Aslam HM, Mughal A, Edhi MM, Saleem S, Rao MH, Aftab A, et al. Assessment of pattern for consumption and awareness regarding energy drinks among medical students. Arch Public Health. 2013;71:31.

7. Nicholson AN, Stone BM. Heterocyclic amphetamine derivatives and caffeine on sleep in man. Br J Clin Pharmacol. 1980;9:195-203.

8. Lane JD, Pieper CF, Phillips-Bute BG, Bryant JE, Kuhn CM. Caffeine affects cardiovascular and neuroendocrine activation at work and home. Psychosom Med. 2002;64: 595-603.

9. Cooke BK, Cooke EO, Sharfstein SS. Evaluating the workload of on-call psychiatry residents: Which activities are associated with sleep loss? Acad Psychiatry. 2012;36:43-46

10. Johns MW. A new method for measuring daytime sleepiness: The Epworth sleepiness scale. Sleep. 1991;14: 540-545.

11. Johns MW. Reliability and factor analysis of the Epworth Sleepiness Scale. Sleep. 1992;15:376-381.

12. Buysse DJ, Reynolds CF, 3rd, Monk TH, Berman SR, Kupfer DJ. The Pittsburgh Sleep Quality Index: A new instrument for psychiatric practice and research. Psychiatry Res. 1989;28:193-213.

13. Spira AP, Beaudreau SA, Stone KL, Kezirian EJ, Lui LY, Redline S, et al. Reliability and validity of the Pittsburgh Sleep Quality Index and the Epworth Sleepiness Scale in older men. J Gerontol A Biol Sci Med Sci. 2011;67:433-439.

14. Lazarus RS, Folkman S. Stress, Appraisal, and Coping. New York: Springer Pub Co; 1984. 
15. Cohen S, Kamarck T, Mermelstein R. A global measure of perceived stress. J Health Soc Behav. 1983;24:385-396.

16. Cohen S, Williamson G. Perceived stress in a probability sample of the United States. In: The Social Psychology of Health: Claremont Symposium on Applied Psychology. S. Spacapam and S. Oskamp (Eds). Newbury Park, CA: Sage; 1988: pp. 31-67.

17. Vignatelli L, Plazzi G, Barbato A, Ferini-Strambi L, Manni R, Pompei F, et al. Italian version of the Epworth sleepiness scale: External validity. Neurol Sci. 2003;23: 295-300.

18. Sgalla G, Cerri S, Ferrari R, Ricchieri MP, Poletti S, Ori $\mathrm{M}$, et al. Mindfulness-based stress reduction in patients with interstitial lung diseases: A pilot, single-centre observational study on safety and efficacy. BMJ Open Respir Res. 2015;2:e000065.

19. Grosso G, Marventano S, Galvano F, Pajak A, Mistretta A. Factors associated with metabolic syndrome in a mediterranean population: Role of caffeinated beverages. J Epidemiol. 2014;24:327-333

20. Centers for Disease Control and Prevention. Energy drink consumption and its association with sleep problems among U.S. service members on a combat deployment-Afghanistan, 2010. MMWR Morb Mortal Wkly Rep. 2012;61:895-898.

21. Papp KK, Stoller EP, Sage P, Aikens JE, Owens J, Avidan A, et al. The effects of sleep loss and fatigue on residentphysicians: A multi-institutional, mixed-method study. Acad Med. 2004;79:394-406.

22. (ACGME) ACfGME. Resident duty hours: duty hourslanguage. http://wwwacgmeorg/acWebsite/dutyHours/ dh_Lang703pdf 2007 (accessed July 11, 2016).

23. Orton DI, Gruzelier JH. Adverse changes in mood and cognitive performance of house officers after night duty. BMJ. 1989;298:21-23.

24. Asken MJ, Raham DC. Resident performance and sleep deprivation: A review. J Med Educ. 1983;58:382-388.

25. Prather AA, Rabinovitz M, Pollock BG, Lotrich FE. Cytokine-induced depression during IFN-alpha treatment: The role of IL-6 and sleep quality. Brain Behav Immun. 23:1109-1116.

26. Curless R, French JM, James OF, Wynne HA. Is caffeine a factor in subjective insomnia of elderly people? Age Ageing. 1993;22:41-45.

27. Sin CW, Ho JS, Chung JW. Systematic review on the effectiveness of caffeine abstinence on the quality of sleep. J Clin Nurs. 2009;18:13-21.
28. Wust S, Federenko I, Hellhammer DH, Kirschbaum C. Genetic factors, perceived chronic stress, and the free cortisol response to awakening. Psychoneuroendocrinology. 2000;25:707-720.

29. Kim HJ, Kim JH, Park KD, Choi KG, Lee HW. A survey of sleep deprivation patterns and their effects on cognitive functions of residents and interns in Korea. Sleep Med. 2011;12:390-396.

30. Reed DA, Fletcher KE, Arora VM. Systematic review: Association of shift length, protected sleep time, and night float with patient care, residents' health, and education. Ann Intern Med. 2010;153:829-842.

31. Fruchtman Y, Moser AM, Perry ZH. Fatigue in medical residents-lessons to be learned. Med Lav. 2011;102: 455-463.

32. Suozzo AC, Malta SM, Gil G, Tintori F, Lacerda SS, Nogueira-Martins LA. Attention and memory of medical residents after a night on call: A cross-sectional study. Clinics (Sao Paulo) 2011;66:505-508.

33. Clark I, Landolt HP. Coffee, caffeine, and sleep: A systematic review of epidemiological studies and randomized controlled trials. Sleep Med Rev. 2016. DOI: 10.1016/j.smrv.

34. Philip P, Taillard J, Moore N, Delord S, Valtat C, Sagaspe $\mathrm{P}$, et al. The effects of coffee and napping on nighttime highway driving: A randomized trial. Ann Intern Med. 2006;144:785-791.

35. Blois R, Gaillard JM, Attali P, Coquelin JP. Effect of zolpidem on sleep in healthy subjects: A placebo-controlled trial with polysomnographic recordings. Clin Ther. 1993;15:797-780

36. Al Sawah M, Ruffin N, Rimawi M, Concerto C, Aguglia E, Chusid E, Infortuna C, Battaglia F. Perceived stress and coffee and energy drink consumption predict poor sleep quality in podiatric medical students. J Am Podiatr Med Assoc. 2015;105:429-434.

Address correspondence to: Fortunato Battaglia, MD, PhD Department of Health and Medical Sciences Seton Hall University 400 South Orange A South Orange, NJ 07079

E-mail: fortunato.battaglia@shu.edu 